\title{
Regulation of the Costimulator B7, Not Class II Major Histocompatibility Complex, Restricts the Ability of Murine Kidney Tubule Cells to Stimulate CD4 ${ }^{+}$T Cells
}

David T. Hagerty, * Brian D. Evavold, ${ }^{\star}$ and Paul M. Allen ${ }^{*}$

${ }^{*}$ Renal Division, Department of Medicine, Jewish Hospital, and ${ }^{\ddagger}$ Department of Pathology, Washington University School of Medicine, St. Louis, Missouri 63110

\begin{abstract}
The proximal segment of murine kidney tubule cells (KTC) constitutively expresses low levels of class II major histocompatibility complex (MHC) that are upregulated during local and systemic inflammation. It is not known if KTC also express the costimulator molecules necessary for them to productively participate in immune responses and stimulate $T$ cells. To answer this question, we studied the ability of KTC to present antigens to four Th1 clones. KTC did not induce $\mathrm{T}$ cell proliferation to specific antigen, superantigen, or concanavalin A. However, $\mathrm{T}$ cell receptors did engage the peptide/MHC ligand presented by KTC, as indicated by $\mathrm{T}$ cell enlargement and upregulation of interleukin-2 receptor expression. Importantly, KTC failed to express the Th1 costimulator, B7, as detected by fluorescence cytometry and reverse transcription polymerase chain reaction. We directly demonstrated that lack of $B 7$ expression accounted for at least part of the KTC presentation defect, in that a KTC line transfected with the CDNA for $B 7$ stimulated $T$ cell proliferation to antigen. Our results suggest that epithelial cells expressing class II MHC have developed mechanisms to prevent costimulator expression and limit parenchymal tissue destruction. Failure of class II-expressing epithelial cells to limit costimulator expression may be an important component of organ-specific autoimmunity. (J. Clin. Invest. 1994. 93:1208-1215.) Key words: antigen-presenting cells $\bullet$ histocompatibility antigens, class II • kidney diseases • kidney tubules, proximal $\cdot T$ lymphocytes
\end{abstract}

\section{Introduction}

The expression of class II major histocompatibility complex (MHC) molecules is predominantly limited to professional an-

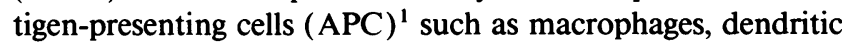
cells, and B cells. However, certain specialized epithelia, such as the thymus and small intestine, also constitutively express class II MHC molecules (1-3). The murine proximal tubule (PT) is another epithelium that constitutively expresses low

Address correspondence to Dr. David T. Hagerty, Department of Pathology, Box 8118, Washington University School of Medicine, St. Louis, MO 63110.

Received for publication 7 September 1993 and in revised form 5 November 1993.

1. Abbreviations used in this paper: APC, antigen-presenting cell(s); ECDI, 1-ethyl-3-(3-dimethyl-aminopropyl) carbodiimide; KTC, kidney tubule cell(s); PT, proximal tubule; $R$, receptor; SEA, staphylococcal enterotoxin A; TCR, T cell receptor.

J. Clin. Invest.

(C) The American Society for Clinical Investigation, Inc.

0021-9738/94/03/1208/08 \$2.00

Volume 93, March 1994, 1208-1215 levels of class II MHC molecules (4-6) and significantly upregulates class II expression in response to systemic infection (6), graft-vs.-host disease (7), and allograft rejection (8). The physiological purpose of PT class II expression, and whether PT class II MHC expression alone will allow these cells to function as a conventional APC and participate in local immune responses, is not known. However, a variety of data suggest that kidney tubule cells (KTC) may function as APC. Inflammation in the renal interstitium frequently plays a critical role in the progression of a variety of kidney diseases. Studies from Schainuck et al. (9), examining a large group of patients with a variety of glomerular diseases, led to the conclusion that loss of renal function was most closely correlated to interstitial changes observed around the renal tubules. The important role of tubulointerstitial inflammation in the ultimate loss of renal function was noted by other investigators in human as well as animal models of glomerular disease (10-13). More specifically, in a variety of glomerular inflammatory diseases as dissimilar as SLE nephritis and IgA nephropathy, T cells infiltrating the interstitium but not the glomerulus have correlated with the loss of renal function (14-16). An important but unresolved question is whether the KTC or some other cell in the interstitium is presenting antigen to the $T$ cells.

Studies from our laboratory using freshly isolated KTC have shown that the PT, in addition to expressing class II MHC molecules, is capable of processing and presenting self as well as foreign antigens in vivo to $\mathrm{CD}^{+}{ }^{+} \mathrm{T}$ cell hybridomas (6). Studies from V. Rubin-Kelley and colleagues examining transformed PT cell lines treated with IFN- $\gamma$, have also demonstrated that KTC can process and present foreign protein antigens to $\mathrm{T}$ cell hybridomas (17). Interestingly, these investigators demonstrated in an in vivo murine model of SLE that PT expression of class II MHC molecules preceded the tubulointerstitial nephritis and loss of renal function, suggesting that the PT may in fact play an important role in the initiation of nephritis (18). In most of these diseases, however, concomitant infiltration of the interstitium with class II-expressing mononuclear macrophages or dendritic cells has accompanied the lymphocytic infiltration (14). Thus the antigen presenting role of the PT in vivo remains undefined.

While the expression of class II MHC/peptide antigen is sufficient to stimulate lymphokine production by most $\mathrm{T}$ cell hybridomas, APC must express additional costimulatory molecules to stimulate $\mathrm{CD}^{+}$Th clone proliferation (19). It is not known if PT cells, or any other epithelial cells, provide this costimulation. We now show that with Thl clones the $\mathrm{T}$ cell receptor (TCR) is engaged by peptide/class II MHC on the KTC but the clones do not proliferate. We also demonstrate that, even after activation of the KTC by systemic infection, the Th1 costimulator molecule B7 is not expressed. Despite expressing immunogenic complexes without B7, however, KTC do not reliably anergize Th1 clones. Transfection of a 
cortical kidney tubule cell line with the cDNA for B7 allows Th1 clones to proliferate to antigen presented by the $B 7$ transfectants. Thus, regulation of B7 expression, and not simply class II MHC, may be a critical feature of PT cell antigen presentation function.

\section{Methods}

Mice. Female $\mathrm{CBA} / \mathrm{JCr}$ mice were purchased from the National Cancer Institute (Bethesda, MD), maintained in a pathogen-free room, and killed at 6-24 wk of age. B10.BR mice were purchased from the Jackson Laboratory (Bar Harbor, ME) at 6-8 wk of age. The transgenic mouse line $\mathrm{Tg}(\mathrm{SV} 40 \mathrm{E})$ Bri7 was obtained from Dr. Ralph Brinster (University of Pennsylvania, Philadelphia, PA) and the $\mathrm{H}-2^{\mathbf{k}}$ haplotype introduced by breeding with $\mathrm{CBA} / \mathrm{J}$ mice.

$T$ cell hybridomas and clones. YO1.6 is a T cell hybridoma restricted by $I-E^{k}$ that recognizes the peptide fragment (64-76) of the $d$ allele on the $\beta$ minor chain of murine hemoglobin [abbreviated $\mathrm{Hb}(64-76)]$. The Th1 clones PL.17, 3.L2, and Hb\#2 recognize $\mathrm{Hb}(64-76)$ in the context of I-E ${ }^{k}(20)$. The Th1 clone AR.2N6 recognizes a hen egg-white lysozyme peptide, abbreviated $\operatorname{HEL}(18-33)$, in the context of I-A $A^{k}(21)$. Clones were maintained on a biweekly passage schedule and used in experiments no sooner than $14 \mathrm{~d}$ after passage. Before use in experiments, clones were treated with anti-class II MHC antibody-coated magnetic beads to remove any contaminating APC before use in experiments. In all assays, clones were routinely cultured with peptide (not protein) antigen alone since experiments indicated that culture of clones with peptide antigen was more sensitive at excluding APC carryover from the Thl cultures. In no experiment was this background proliferation $>1500 \mathrm{cpm}$. T cell hybridomas and clones were passaged in RPMI 1640 (Gibco Laboratories, Grand Island, NY) supplemented with $10 \%$ bovine serum (Hyclone Laboratories, Inc., Logan, UT), $2 \mathrm{mM}$ glutamine, $50 \mu \mathrm{g} / \mathrm{ml}$ gentamicin, and 2 $\times 10^{-5} \mathrm{M} 2$-mercaptoethanol.

Induction of KTC cell class II MHC expression by L. monocytogenes infection. CBA/J mice 6-24 wk of age were given $2 \times 10^{4}$ live Listeria monocytogenes i.p. in $\mathrm{PBS}\left(\mathrm{LD}_{\mathrm{s0}}=1 \times 10^{5}\right.$ bacteria $)$ and the kidneys removed between days 8 and 14 .

Preparation of KTC. KTC were isolated by a modification of the method of Vinay et al. (22). With this protocol, tubules enriched in the proximal segment are isolated from a continuous Percoll (Pharmacia Inc., Piscataway, $\mathrm{NJ}$ ) gradient at $\sim 1.23 \mathrm{~g} / \mathrm{ml}$, a density that we have found to be free of contamination from $\mathrm{B}$ cells, macrophages, and dendritic cells, which have densities of $<1.010 \mathrm{~g} / \mathrm{ml}(6,23)$. Kidney tubule segments were then digested with trypsin $0.05 \%$ (Sigma Chemical Co., St. Louis, MO) and $1 \mathrm{mM}$ EDTA (Sigma Chemical Co.) in PBS for 10 min with continuous shaking. The remaining supernatant contained predominantly single PT cells. Experiments in which these cells were further adhered for $2 \mathrm{~h}$ in $10 \%$ serum (to remove macrophages) followed by treatment with a cocktail of antibodies against $B$ cell (anti-mouse-IgG $+\mathrm{M}$ and the anti-CD45 $\mathrm{mAb} \mathrm{I}_{3 / 2.3}$ ), macrophage (M1/70), and dendritic cell surface markers $\left(\mathrm{I}_{3 / 2.3}\right)$ and complement, yielded identical results. Thus, we are confident that these tubule preparations are free of conventional APC. On the basis of histochemical staining and class II MHC expression this preparation of KTC is 70$80 \%$ PT cells with the remainder of the cells being other tubule cells. Dead cells were removed by centrifugation through Ficoll (Pharmacia, Inc.) and the remaining viable cells were used in experiments. For experiments using T cell clones only, KTC were irradiated with 2,000 rads to inhibit proliferation.

Production of transformed kidney cortical tubule cell lines. Kidneys were removed from 6-wk-old [ $\mathrm{Tg}(\mathrm{SV} 40 \mathrm{E}) \mathrm{Bri} 7 \times \mathrm{CBA} / \mathrm{JCr}] \mathrm{F} 1$ mice and PT segments removed by an experienced kidney tubule microperfusionist (Dr. L. Lee Hamm, Tulane University, New Orleans, LA). Tubule segments were placed into a 50:50 mixture of serum-free RPMI/Ham's F12 to which insulin $5 \mu \mathrm{g} / \mathrm{ml}$, transferrin $5 \mu \mathrm{g} / \mathrm{ml}$, thyroxine $3.5 \mathrm{ng} / \mathrm{ml}$, sodium selenite $1.75 \mathrm{ng} / \mathrm{ml}$, EGF $15 \mathrm{ng} / \mathrm{ml}$, 2-mer- captoethanol $2 \times 10^{-5} \mathrm{M}$, and gentamicin $50 \mu \mathrm{g} / \mathrm{ml}$ was added (complete media). Cells that grew from the explants were cloned by limiting dilution and examined for antigen presentation functions. Only cell lines whose antigen-presenting phenotype mimicked that of freshly isolated PT cells were further characterized. These cells stained positively for alkaline phosphatase and nonspecific esterase and produced cAMP in response to parathyroid hormone as well as antidiuretic hormone. In addition, these cells expressed high basal levels of intercellular adhesion molecule-1 (ICAM-1) and upregulated class II MHC expression with IFN- $\gamma$ treatment. Thus the cells exhibit predominantly a PT phenotype. The cell line 1-1D3 was the representative cell line used in these experiments.

Transfection of the transformed kidney cortical tubule cell line 1-1D3 with murine B7. Subconfluent cultures of 1-1D3 in six-well plates were mixed with the Lipofectin reagent (Gibco BRL, Gaithersburg, MD) and $10 \mu \mathrm{g}$ of the cDNA for murine B7 in the BCMG vector ( $\mathrm{mB} 7-\mathrm{BCMG}$, kindly provided by Dr. Casey Weaver, University of Alabama at Birmingham, Birmingham, AL) (24). G418-resistant cells were expanded and cloned by limiting dilution. Transfectants (D3.B7) were screened for $B 7$ expression by fluorescence cytometry and reverse transcription (RT) PCR.

Analysis of KTC for B7 by RT-PCR. Freshly isolated KTC were prepared from normal mice or mice injected with $L$. monocytogenes 8-14 d previously or from the various transformed KTC lines. The cells were washed in RNase-free PBS and RNA isolated as described by Gough (25). First strand cDNA synthesis was performed using SuperScript RT (Gibco BRL). To amplify the cDNA for B7, PCR was performed on a DNA thermal cycler (Perkin-Elmer Cetus Corp., Norwalk, CT) using the primers: 5' TAAGGTATTGCTGCCTTGCC and 3' TCTGACACGTGAGCATCTCC. These primers amplify a 546-bp fragment. As a control, RT-PCR of the murine IFN- $\gamma$ receptor was performed simultaneously using the primers: $5^{\prime}$ TTGCAGATCTGCACGTGACGCCAAGGCCAGGC and 3' ACTAGATCTCTCTTACTTCTTAGTATACCAATACG. These primers amplify a 1kb fragment. The PCR-amplified products were electrophoresed through a $3 \%$ agarose gel (NuSieve, FMC BioProducts, Rockland, ME) and bands identified by ethidium bromide staining.

Fluorescence cytometry. Thl clones were cultured either alone, with APC alone, or with APC and antigen for 24-48 h. The cells were resuspended and layered onto Ficoll ( $1.077 \mathrm{~g} / \mathrm{ml}$, Pharmacia, Inc.), and the viable $\mathrm{T}$ cell clones were harvested, washed, and stained for 30 min on ice with primary antibodies. Cells were then washed and stained with a FITC-conjugated secondary antibody directed against the primary antibody. $T$ cell clones were analyzed for size by forward light scatter and for the surface expression of CD3 $\epsilon$, Thy 1.2, CD4, and IL-2 receptor ( $R$ ) using a Becton-Dickinson (Mountain View, CA) FACScan. The anti-CD3 $\epsilon$ mAb 145-2C11 was obtained from Dr. J. Bluestone and anti-Thy 1.2 mAb AT83A from Dr. F. Fitch. The antiCD4 mAb GK1.5 and anti-IL-2R mAb 7D4 were obtained through the American Type Culture Collection (Rockville, MD). FITC-conjugated secondary antibodies were obtained from Jackson ImmunoResearch (West Grove, PA). To characterize the KTC and D3.B7 transfectants for the surface expression of B7, cells were incubated either with the control antibody anti-CD3 (145-2C11), the anti-B7 monoclonal Ab 16-10Al (kindly provided by Dr. Hans Reiser, Dana Farber Cancer Institute, Boston, MA), buffer alone, or CTLA4Ig (BristolMyers Squibb Pharmaceutical Research Institute, Seattle, WA). After $30 \mathrm{~min}$ on ice, the cells were washed and stained with goat anti-hamster Ig-FITC (Jackson ImmunoResearch; anti-CD3 and anti-B7stained cells) or a polyclonal goat anti-human $\alpha, \gamma, \mu$-chain specific PE-conjugated antibody (Sigma Chemical Co.; buffer alone and CTLA4Ig-stained cells).

Antigens, enterotoxins, and mitogens. $\mathrm{Hb}(64-76)$ and $\mathrm{HEL}(18-33)$ were synthesized on a DuPont RaMPS apparatus (Wilmington, DE) using 9-fluorenylmethoxycarbonyl chemistry and purified by reversephase HPLC as previously described (26). Staphylococcal enterotoxin A (SEA) was obtained from Toxin Technology (Sarasota, FL). HEL protein and Con A were purchased from Sigma Chemical Co. 
Antigen presentation assays. Freshly isolated KTC (3-5 $\times 10^{4} /$ well) were cultured with the $\mathrm{T}$ cell hybridomas $\left(10^{5} /\right.$ well $)$ or $\mathrm{T}$ cell clones (3-5 $\times 10^{4} /$ well) in 96-well flat-bottomed plates (Costar, Cambridge, MA), either with or without antigen in a final volume of $0.2 \mathrm{ml}$. Culture media consisted of complete media with $10 \%$ bovine serum (Hyclone Laboratories, Inc.). To measure T cell hybridoma stimulation or Th 1 clone IL-2 production, $0.1 \mathrm{ml}$ of supernatant was removed after 18-24 $\mathrm{h}$ of culture and added to the IL-2/4-dependent cell line CTLL-2 $\left(5 \times 10^{3} /\right.$ well $)$. Wells were pulsed with $\left[{ }^{3} \mathrm{H}\right]$ thymidine $(0.4$ $\mu \mathrm{Ci} /$ well) after $18-24 \mathrm{~h}$ and quantification of IL-2 production was measured as $\left[{ }^{3} \mathrm{H}\right]$ thymidine incorporation. For $\mathrm{T}$ cell clone proliferation assays, wells were pulsed with $\left[{ }^{3} \mathrm{H}\right]$ thymidine $(0.4 \mu \mathrm{Ci} /$ well $)$ after $42-48 \mathrm{~h}$ of culture and harvested the next day. Proliferation was measured as $\left[{ }^{3} \mathrm{H}\right]$ thymidine incorporation. For experiments using Con $\mathrm{A}$, Th1 clones were cultured with T-depleted spleen cells (GK1.5 and AT83A treatment followed by complement, as previously described [27]) or KTC and Con A (1-5 $\mu \mathrm{g} / \mathrm{ml})$. Wells were pulsed with [ $\left.{ }^{3} \mathrm{H}\right]-$ thymidine $(0.4 \mu \mathrm{Ci} /$ well $)$ after $66-72 \mathrm{~h}$ and harvested the next day. All assays were performed in a final volume of $0.2 \mathrm{ml}$.

Tolerization induction assays. T cell clones $\left(5 \times 10^{5} /\right.$ well $)$ were cultured in 24-well plates with either live, freshly isolated KTC $\left(10^{6} /\right.$ well), freshly isolated KTC plus peptide antigen, 1-ethyl-3-(3-dimethyl-aminopropyl) carbodiimide (ECDI, Calbiochem Corp., LaJolla, CA $)$-fixed splenic APC $\left(5 \times 10^{5} /\right.$ well $)$, or ECDI-fixed splenic APC plus peptide antigen, as previously described (28). In some experiments, APC were fixed with $1 \%$ paraformaldehyde for $10 \mathrm{~min}$ at room temperature instead of ECDI and identical results were obtained. After 48-72 $\mathrm{h}$, the cells were resuspended and viable $\mathrm{T}$ cells recovered from a Ficoll gradient. These $\mathrm{T}$ cells were then rechallenged with antigen on live irradiated splenic APC as in the usual antigen presentation assay.

\section{Results}

$K T C$ do not stimulate the proliferation of $C D 4^{+}$Th1 clones. Because previous experiments had shown that freshly isolated $\mathrm{KTC}$ can process and present self as well as foreign antigens to T cell hybridomas (6), we wished to determine if KTC were able to provide the additional costimulatory signals required to stimulate Ag-specific Thl clone proliferation. The I-Ek-restricted Th 1 clone PL. 17 proliferated vigorously to $\mathrm{Hb}(64-76)$ presented by syngeneic spleen cells, but failed to do so when KTC were used as the APC (Fig. $1 A$ ). Culture of PL.17 with syngeneic spleen cells and antigen also led to easily detectable IL-2 production, as determined by the proliferative response of the IL-2/4-dependent cell line CTLL-2 (Fig. $1 B$ ). Culture of PL. 17 with KTC and antigen, however, failed to trigger IL-2 production. Simultaneous experiments with the T cell hybridoma YO1.6 confirmed that the KTC expressed immunogenic complexes capable of recognition (Fig. $1 C$ ), although the concentration of antigen necessary to stimulate equivalent levels of IL-2 production was consistently 10 - to 100 -fold greater when KTC were used as APC compared to spleen cells. Identical results were obtained with a larger panel of Th1 clones, 2 of which recognized $\mathrm{Hb}(64-76)$ in the context of $I-E^{k}$ and one that recognized HEL (18-33) in the context of $I-A^{k}$. Similar results were obtained with antigen concentrations as high as $316 \mu \mathrm{M}$.

We also wished to examine whether other stimuli capable of triggering Thl proliferation in the presence of professional APC would trigger Th1 proliferation with KTC. Th1 clones were cultured with Con $\mathrm{A}$ and either $\mathrm{T}$ cell-depleted splenic APC or KTC. Again, the clones proliferated only when cultured on the splenic APC $(23,077 \mathrm{cpm})$ and not on the KTC $(<150 \mathrm{cpm})$. Similar results were obtained when PL.17, a $\mathrm{V}_{\beta} 1^{+}$clone that proliferates to the superantigen SEA only in the presence of APC expressing costimulators (Dr. Evavold, unpublished data), was cultured with $\mathrm{T}$ cell-depleted splenic APC or KTC: SEA triggered proliferation only when PL. 17 was stimulated on the $T$ cell-depleted splenic APC (data not shown). Taken together, this series of experiments showed that although KTC expressed recognizable immunogenic peptide/ class II MHC complexes capable of engaging the TCR, this was insufficient to stimulate Th1 proliferation or IL-2 production.

$K T C$ induce Thl signaling through the TCR. Because the Th 1 clones did not proliferate or produce IL- 2 when presented antigen on the KTC, we wished to determine if the KTC were delivering any signal to the $T$ cells. Visual inspection of the Thl clones when stimulated with antigen and KTC suggested that the clones were enlarging and entering the cell cycle. Th1 clones were therefore cultured with either antigen alone, spleen or KTC alone, or APC plus antigen for 24-48 h in 24-well plates and the viable $T$ cells analyzed for evidence of $T$ cell
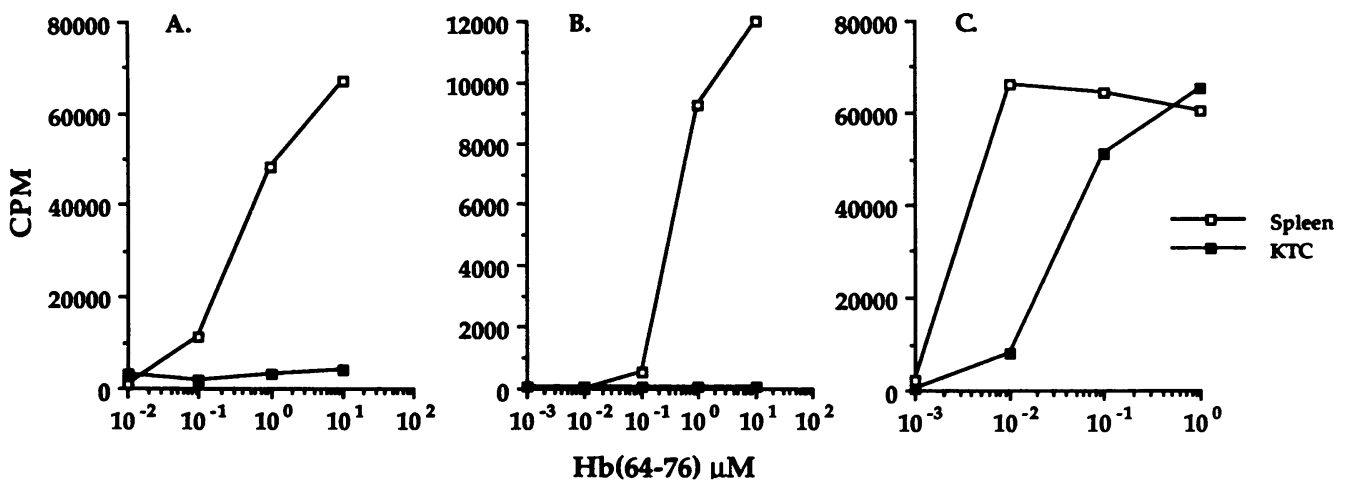

Figure 1. Freshly isolated KTC do not stimulate Th1 proliferation. $(A)$ Thl clones $\left(3 \times 10^{4} /\right.$ well $)$ were cultured in 96-well plates with $\mathrm{Hb}(64-76)$ and B10.BR spleen cells $\left(5 \times 10^{5} /\right.$ well $)$ or freshly isolated KTC cells from $L$. monocytogenestreated mice $\left(3 \times 10^{4} /\right.$ well $)$. Wells were pulsed with $\left[{ }^{3} \mathrm{H}\right]-$ thymidine $48 \mathrm{~h}$ later and harvested at $72 \mathrm{~h}$. The data shown is from a representative experiment using PL.17 $(n>6)$. Similar data was obtained with the other Th1 clones, all of which were tested at least three times. Proliferation of the clones to peptide antigen alone was less than 1500 CPM. ( $B$ ) PL.17 produces IL-2 when stimulated by antigen presented on splenic APC but not on KTC. The experiment was performed as in $A$ except that supernatants were removed at $48 \mathrm{~h}$ and added to the IL-2/4-dependent cell line, CTLL-2. Stimulation of PL.17 was assessed as CTLL-2 $\left[{ }^{3} \mathrm{H}\right]$ thymidine incorporation. The data shown is from a representative experiment $(n=3)$. $(C)$ Immunogenic complexes are present on the KTC and available for immune recognition. The T cell hybridoma YO1.6 ( $10^{5} /$ well $)$ was cultured in 96-well plates with $\mathrm{Hb}(64-76)$ and B10.BR spleen cells $\left(5 \times 10^{5} /\right.$ well $)$ or freshly isolated KTC cells from L. monocytogenes-treated mice $(3 \times$ $10^{4} /$ well ). Supernatants were removed at $24 \mathrm{~h}$ and added to the IL-2/4-dependent cell line CTLL-2. Stimulation of the hybridoma was quantitated as the $\left[{ }^{3} \mathrm{H}\right]$ thymidine incorporation of CTLL-2. (ם) Splenic APC; (匹) KTC APC. 
A.

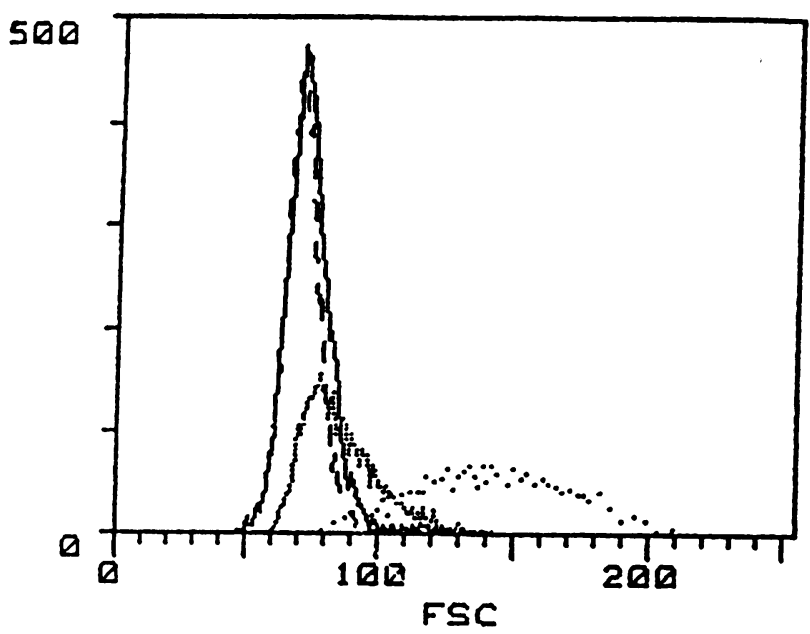

B.

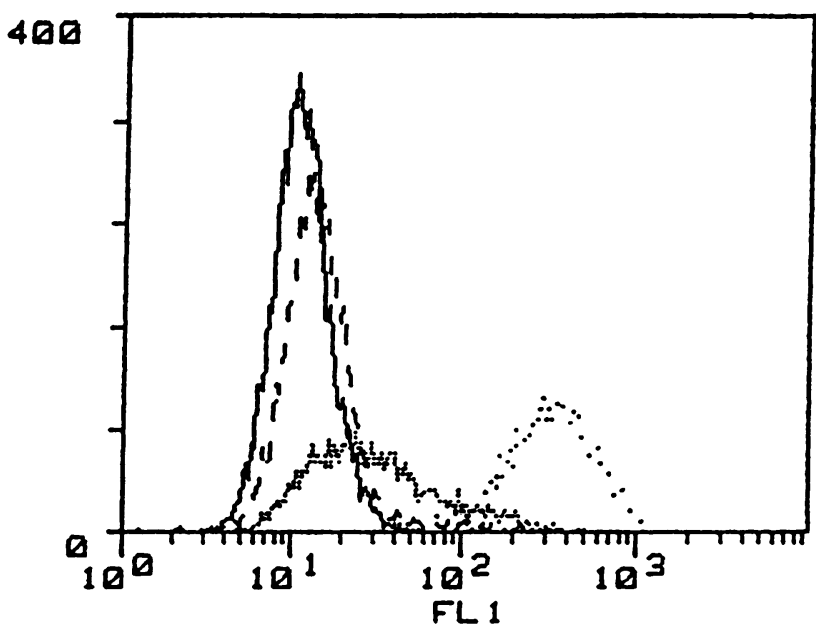

Figure 2. Th1 clones stimulated by KTC cells and antigen enlarged and upregulated IL-2R expression. Thl clones were stimulated as described and stained for fluorescence cytometry analysis. Clones stimulated with antigen on KTC or splenic APC underwent a significant increase in cell size as assessed by $(A)$ forward light scatter (FSC) and $(B)$ upregulated expression of IL-2R. Dead cells were gated out by FSC and side scatter (SSC) measurements. At $48 \mathrm{~h}$, cell recoveries were 30-40\% for T cells cultured without antigen on splenic APC or KTC, 50-60\% for T cells cultured with antigen on KTC, and $75-85 \%$ for T cells cultured with antigen on splenic APC. T cells stimulated with antigen alone ( -$)$, splenic APC alone $(---)$, KTC plus antigen $(\cdots \cdots \cdots \cdots)$, and splenic APC plus antigen $(\cdots \cdots)$

activation using fluorescence cytometry. FSC measurements confirmed that KTC and antigen induced enlargement of the Th1 clones (Fig. $2 A$ ). In addition, the clones demonstrated significant upregulation of the IL-2R (Fig. $2 B$ ). No changes in CD4, Thy 1.2, or CD3 were demonstrable (data not shown). These changes were consistent with cell cycle progression into G1 phase and suggested that the KTC deliver some signal to the Th 1 cells that results in an increase in cell size and upregulation of the IL-2R.

KTC fail to express $B 7$ and are not toxic to Thl clones. To explore the possibility that the failure of KTC to fully stimulate the Th1 cells was due to lack of costimulator expression, we analyzed both KTC from normal mice as well as KTC from mice infected with L. monocytogenes for the expression of B7 by fluorescence cytometry using the anti-B7 mAb $16-10 \mathrm{Al}$ as well as the fusion protein CTLA4Ig (Fig. 3, $A$ and $B$ ). We could not detect B7 or any B7-like molecules on any of the KTC. The data shown is that obtained using 16-10Al. Identical results were obtained using CTLA4Ig (data not shown). To examine whether the KTC might only express low levels of B7 undetectable by fluorescence cytometry, we isolated RNA from the different KTC preparations and performed RT-PCR (Fig. 4). Again, no detectable B7 was observed from KTC prepared either from normal mice or L. monocytogenes-infected mice, while the B cell lymphoma $\mathrm{CH} 27$ demonstrated $\mathrm{B} 7$ surface expression (Fig. $3 C$ ) and mRNA (Fig. 4). The relatively lowabundance mRNA for the murine IFN- $\gamma$ receptor was detectable in these RNA preparations, confirming the sensitivity of the assay. These experiments provided convincing evidence that even with the strong stimulus of a systemic infection, KTC failed to express the Th1 costimulator B7.

To rule out the possibility that the KTC exerted a toxic or inhibitory effect on the Th1 clones, mixing experiments were performed. Splenic APC and Th1 clones were cultured either alone or with various concentrations of KTC and the proliferative response of the Thl clones to specific antigen determined (Fig. 5). At the concentration of KTC used in these assays, minimal KTC inhibition of Th1 proliferation was observed,
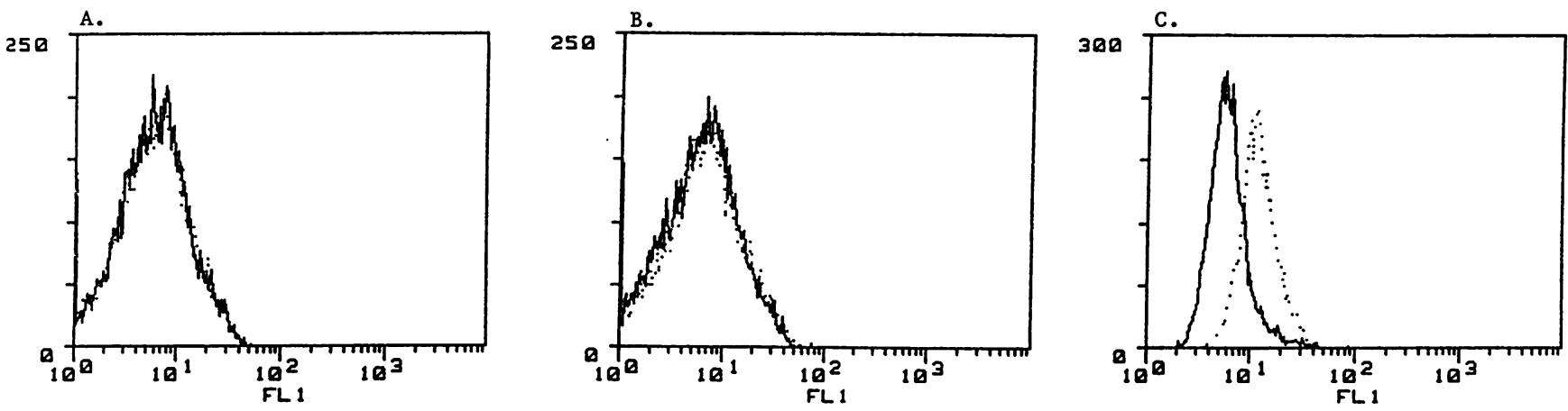

Figure 3. KTC from normal mice as well as from $L$. monocytogenes-treated mice do not express the Th1 costimulator, B7. KTC were prepared as described from either normal $(A)$ or $L$. monocytogenes-treated $(B)$ mice and incubated with an anti-B7 mAb $(16-10 \mathrm{~A} 1,10 \mu \mathrm{g} / \mathrm{ml})$ or the control hamster antibody anti-CD3 (145-2C11), followed by goat anti-hamster Ig-FITC. As a positive control, the B cell lymphoma CH27 $(C)$ was stained with the same reagents. Solid line: control mAb. Dotted line: anti-B7 mAb. 


\section{$\begin{array}{lllllllllllll}1 & 2 & 3 & 4 & 5 & 6 & 7 & 8 & 9 & 10 & 11 & 12 & 13\end{array}$}

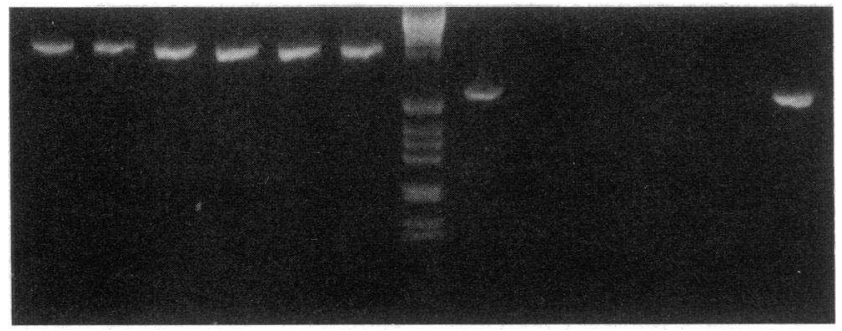

Figure 4. RT-PCR fails to detect B7 expression in normal or activated KTC. RNA was prepared from KTC isolated from normal mice as well as from L. monocytogenes-treated mice, $\mathrm{CH} 27$, the KTC-transformed cell line 1-1D3, and two B7-transfected KTC lines. Firststrand CDNA synthesis was performed and used as a template in the PCR reaction for the detection of $B 7$ and murine IFN- $\gamma$ receptor, a low copy number mRNA. The murine IFN- $\gamma$ receptor was detectable in all cells (lanes 1-6) but B7 was detectable only in the control $\mathrm{CH} 27$ cells (lane 13) and the B7-transfected KTC-transformed cell line that was positive for B7 by fluorescence cytometry (lanes 1 and 8 ), control B7-transfected KTC line negative for B7 expression by fluorescence cytometry (lanes 2 and 9), parent KTC line used for B7 transfection (lanes 3 and 10), KTC from normal mice (lanes 4 and 11), KTC prepared from Listeria-infected mice (lanes 5 and 12), B cell lymphoma CH27 (lanes 6 and 13), 1-kb DNA ladder (lane 7).

although at higher numbers of KTC $\left(>10^{5} /\right.$ well $)$, progressive inhibition of proliferation was seen (data not shown). In addition, we addressed this issue two additional ways. Th1 clones ( 5 $\times 10^{5} /$ well $)$ were cultured with either KTC alone $\left(10^{6} /\right.$ well $)$ or KTC plus $\mathrm{Hb}(64-76) 50 \mu \mathrm{M}$ in 24-well plates. After 24-48 $\mathrm{h}$, the number of viable $\mathrm{T}$ cells was compared to the input number of cells. In all experiments, more viable $\mathrm{T}$ cells were recovered from the wells in which antigen was included (50$60 \%$ viability with antigen vs. $30-40 \%$ viability without antigen), arguing against the possibility that the KTC were inducing antigen-specific programmed cell death in the $\mathrm{T}$ cells, as has been reported for Th 1 clones $(24,29)$. In addition, $T$ cells $(5$ $\times 10^{4} /$ well $)$ were cultured with KTC $\left(5 \times 10^{4} /\right.$ well $)$ and $\mathrm{Hb}(64-76)$ or media alone in 96-well plates, with or without IL-2 $100 \mathrm{U} / \mathrm{ml}$. If the KTC were inducing programmed cell death in the $\mathrm{T}$ cells, one should see less $\mathrm{T}$ cell proliferation at higher antigen doses. In fact, there was no difference in $\mathrm{T}$ cell proliferation both with and without antigen (data not shown).

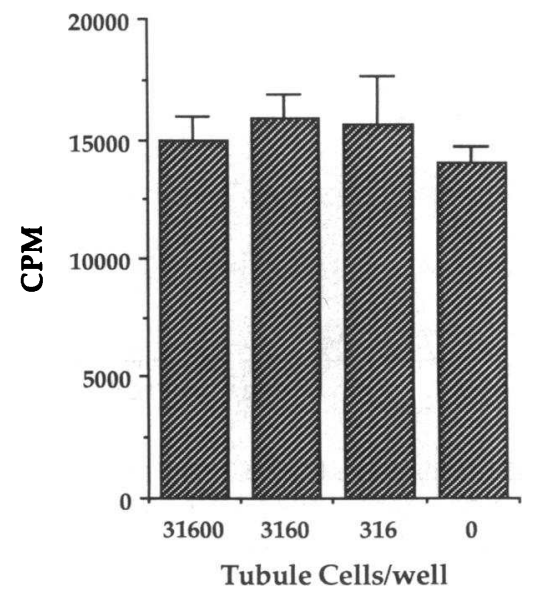

Figure 5. KTC are not toxic to Th1 clones. PL. 17 ( $5 \times 10^{4} /$ well $)$ was cultured in 96-well plates with $\mathrm{Hb}(64-76)$ $10 \mu \mathrm{M}, \mathrm{B} 10 . \mathrm{BR}$ spleen cells $\left(5 \times 10^{5} /\right.$ well $)$, and the indicated numbers of freshly isolated KTC from L. monocytogenes-treated mice. No significant inhibition of Th 1 proliferation was observed at the number of KTC used in the Thl proliferation assays $\left(3 \times 10^{4} /\right.$ well $)$.
These experiments excluded the possibility that the KTC were directly toxic to or killing the Th1 clones.

$K T C$ transfected with $m B 7$ stimulate Th1 proliferation. We wished to directly test the hypothesis that lack of KTC B7 expression accounted for some if not all of the inability of the KTC to stimulate Th 1 proliferation. To test this hypothesis, we generated the cell line 1-1D3, that demonstrated a phenotype similar to that of the proximal tubule (see Methods) and stably transfected it with the cDNA for B7 (D3.B7). This cell line, which also demonstrated an antigen-presenting phenotype similar to that of freshly isolated KTC, was cultured in vitro with IFN- $\gamma$, and examined for the ability to stimulate Th 1 proliferation. PL. 17 proliferated to antigen presented by the B7-expressing cell line but not when a control D3.B7-transfected KTC line that lacked surface as well as mRNA expression of $B 7$ as used as an APC (Figs. 5 and $6 A$ ). Control experiments with the costimulator-independent T cell hybridoma YO1.6 indicated that the two D3.B7 cell lines expressed similar levels of peptide/class II MHC complexes, as evidenced by YO1.6 IL-2 production (Fig. $6 \mathrm{~B}$ ). Thus only the KTC expressing B7 were capable of causing PL.17 proliferation which was completely blocked by anti-B7 antibody (data not shown). These results showed that the failure of KTC to stimulate Th1 proliferation was due at least in part to the inability of the KTC to express B7.

KTC do not consistently anergize Th1 clones. It is currently believed that $\mathrm{Th} 1$ clones stimulated by antigen in the absence of a second costimulatory signal not only fail to proliferate but are instead rendered profoundly anergic to restimulation by antigen (30). Since the Thl clones did not proliferate to antigen presented by KTC, it was important to determine whether the clones were anergized. We therefore performed tolerization assays as described by Jenkins and Schwartz (28) and discovered that KTC were poor inducers of anergy. In all experiments, Thl clones stimulated by antigen on ECDI-fixed APC were completely anergic to restimulation by antigen on live $\operatorname{APC}(<1000 \mathrm{cpm}$, data not shown $)$. Th1 clones stimulated by antigen on live KTC, however, were not anergized $(n=9)$. In a single experiment, significant anergy was observed, but in all other experiments Th1 clones simply required either 10 - to 50 -fold more antigen $(n=2)$ to trigger proliferation equivalent to clones initially stimulated on fixed splenic APC without antigen (negative anergy control) or else were totally unaffected $(n=7)$. The lack of ability to consistently induce Th1 anergy appears to be an important facet of KTC antigen presentation function and not simply due to KTC damage during the isolation procedure since the KTC stimulate T cell hybridoma IL-2 production at least as well as fixed splenic APC that are potent inducers of anergy (data not shown). These results are consistent with the view that while the KTC induce T cell signaling, the signal transduced is either qualitatively or quantitatively different from that transduced on traditional APC and in most cases, not sufficient to induce anergy. Importantly, these results challenge the hypothesis that $\mathrm{Th} 1$ clones encountering antigen/MHC in the absence of costimulatory second signals always results in T cell anergy and indicates that factors other than the expression of class II MHC and costimulator molecules may play important roles in preventing anergy induction.

\section{Discussion}

These studies show that the murine KTC demonstrate unique antigen-presenting functions compared to professional APC. 

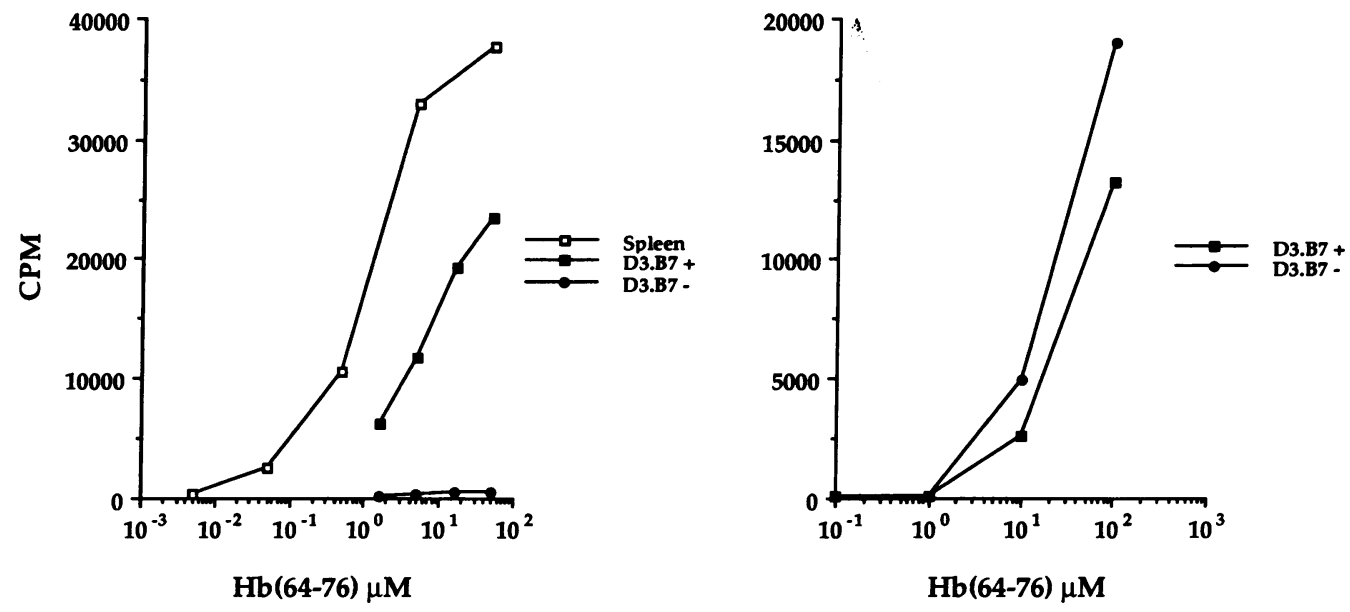

Figure 6. (A) KTC transfected with B7 stimulate Th1 proliferation to specific antigen. PL.17 (3 $\times 10^{4} /$ well $)$ was cultured in 96-well plates with $\mathrm{Hb}(64-76)$ and B10.BR spleen cells $\left(5 \times 10^{5} /\right.$ well $)$; IFN- $\boldsymbol{\gamma}$-treated, transfected 1-1D3 cells expressing B7 (D3.B7+, $3 \times 10^{4} /$ well); or IFN- $\gamma$-treated, transfected (G418-resistant) 1-1D3 cells not expressing $B 7$ by fluorescence cytometry or RT-PCR (D3.B7-, $3 \times 10^{4} /$ well). Wells were pulsed with $\left[{ }^{3} \mathrm{H}\right]$ thymidine $48 \mathrm{~h}$ later and harvested at $72 \mathrm{~h}$. The data shown is from a representa-

tive experiment using PL.17 $(n=2)$. (B) Lack of B7 expression does not affect the presentation of $\mathrm{Hb}(64-76)$ to the costimulator-independent T cell hybridoma YO1.6. KTC from the same experiment shown in $A$ were also cultured with the T cell hybridoma YO1.6 (105/well) and $\mathrm{Hb}$ (64-76). Culture supernatants were removed the next day and added to the IL-2/4-dependent cell line CTLL-2. Stimulation of T cell hybridoma IL-2 production was assessed as CTLL [ $\left.{ }^{3} \mathrm{H}\right]$ thymidine incorporation. (ם) Splenic APC; (ø) B7-expressing KTC line; (O) B7-transfected control cell line that does not express B7 either by fluorescence cytometry or RT-PCR.

When cultured with KTC and antigen, the TCR of the Th1 cells engaged peptide/MHC and received a signal to enter the G1 phase of the cell cycle, as evidenced by T cell enlargement and upregulation of the IL-2R. However, subsequent cell events were distinct from the events observed with traditional bone marrow-derived APC. Rather than continuing through the cell cycle with resultant IL-2 production and cell proliferation, Th1 clones stimulated on KTC APC did not proliferate or produce IL-2. This was true whether the antigenic stimulus was a traditional peptide, a $\mathrm{T}$ cell mitogen, or a bacterial superantigen. Importantly, mixing studies indicated that at the number of KTC used in these experiments, a toxic or inhibitory effect of the KTC on the Th1 clones did not account for these results. These studies were consistent with the hypothesis that PT cells lacked the costimulatory molecules necessary to fully stimulate Th1 proliferation and IL-2 production and that only partial activation of the Thl clones occurred.

It is now known that at least two of the costimulatory factors for Th1 cells are B7 and heat-stable antigen $(31,32)$. Whether epithelial cells express these costimulators was previously unknown. We now show that normal KTC as well as KTC prepared from L. monocytogenes-treated mice, do not express B7. It is interesting in this respect that the IFN- $\gamma$ produced during Listeria infection induced class II MHC upregulation on macrophages and $\mathrm{KTC}(6,33-35)$ and of $\mathrm{B} 7$ on macrophages (36) yet did not upregulate B7 on KTC. These studies suggest that there may be tissue specificity to IFN- $\gamma$ signal transduction or $\mathrm{B} 7$ gene regulation. The regulation and limitation of B7 expression is likely an important facet of the normal physiology of this cell.

The cellular basis for the inability of KTC to stimulate our Th1 clones appeared to be failure to express the costimulator molecule B7. Significantly, the B7-transfected KTC cell line was capable of inducing the Thl clones to proliferate, indicating that lack of B7 expression is one way the KTC may limit its ability to stimulate $\mathrm{CD}^{+} \mathrm{T}$ cells, and therefore potentially limit parenchymal destruction.

Another possibility for the failure of the KTC to trigger Th1 proliferation is that the PT lacks some other normal accessory function. For example, TCR engagement by peptide/MHC results in APC intracytoplasmic signaling $(37,38)$. This signaling has been shown to require the class II cytoplasmic tail and results in the upregulation of $B 7$ expression (39). TCR engagement by specific antigen/MHC also results in a transient increase of T cell / APC affinity mediated by APC ICAM- 1 and T cell LFA-1 (40). Defects within the PT signaling or adhesion pathways upon TCR engagement could also potentially explain our results. The PT may in fact resemble the thymic epithelium, which also fails to stimulate Th1 clones (41).

One of the current theories of peripheral $\mathrm{CD}^{+} \mathrm{T}$ cell tolerance induction postulates that $\mathrm{T}$ cells encountering $\mathrm{Ag} / \mathrm{MHC}$ in the absence of a second costimulatory signal may result in the induction of anergy in that $T$ cell (42). Investigators have attempted to examine this hypothesis by expressing allogeneic class II MHC molecules on the $\alpha$ and $\beta$ epithelial cells of the pancreas by the use of tissue-specific promoters (43). These studies have yielded conflicting data as far as whether $T$ cells in these mice are tolerant in vitro, although none of the mice developed T cell-mediated destruction of allo-MHC-expressing parenchymal cells in vivo. While this type of system for ensuring self tolerance might be advantageous for tissue-specific self antigens not expressed in the thymus, this type of system might be deleterious if foreign antigens were able to anergize a significant portion of the $\mathrm{T}$ cell repertoire during a routine infectious process.

Our results indicate that the PT does not normally appear to function as a professional APC despite constitutively expressing class II MHC and upregulating class II in response to systemic inflammation. However, this failure of the PT cells to either stimulate Th1 proliferation or induce profound anergy may be the critical biologically significant features of KTC antigen presentation function. The kidney is the principal site of IFN- $\gamma$ degradation in the body (44) which may in part explain why the PT expresses class II MHC molecules. This parenchymal class II MHC expression might represent a potentially serious problem for the survival of the organism: if epithelial cells were to function as professional APC, the resulting parenchymal tissue damage due to direct activation of $T$ cells might lead 
to irreversible organ failure in the setting of what would otherwise be an insignificant infection. Thus, organ systems may have developed mechanisms to minimize potentially dangerous parenchymal destruction by preventing $\mathrm{CD}^{+} \mathrm{T}$ cell activation. Although these studies support the hypothesis that the KTC does not normally function as a professional APC, it is possible that under certain pathologic conditions, such as inflammatory renal autoimmune disease, KTC acquire the ability to function as conventional APC or may synergize with other B7-expressing cells $(45,46)$. It is interesting to speculate that the development of interstitial nephritis may therefore not be due to the upregulation of KTC class II MHC expression, but due to the loss of the normal ability of these cells to limit costimulator expression. This may take the form of either the failure of the PT cell to limit B7 expression or adhesion molecules, the failure of either soluble or cell-bound KTC cytokines to inhibit $\mathrm{T}$ cell activation, or a combination of these mechanisms.

One possibility our studies do not address is that KTC may express unique non-B7 costimulators that can provide second signals to nephritogenic or naive $T$ cells, but not to $T$ cells that require B7. A series of studies from Neilson, C. J. Kelly, and co-workers examining autoimmune anti-3M-1 interstitial nephritis are particularly informative (for a recent review, see reference 47). These investigators found that $\mathrm{CD}^{+} \mathrm{T}$ cells from the lymph nodes of mice immunized with $3 \mathrm{M}-1$ adoptively transferred nephritis when injected into naive mice (48, 49). In addition, cloned nephritogenic $\mathrm{CD}^{+} \mathrm{T}$ cells proliferated (although weakly) to $3 \mathrm{M}-1$ antigen presented on the PT cell line, MCT (50). These results suggest that certain subpopulations of $\mathrm{CD}^{+} \mathrm{T}$ cells may be capable of using costimulators provided by PT cells. The PT costimulator activating nephritogenic $\mathrm{CD}^{+} \mathrm{T}$ cells is unknown. Identification of such a costimulator would have obvious importance for the study of $\mathrm{T}$ cell activation as well as for possible new treatments for autoimmune $\mathrm{T}$ cell-mediated diseases and allograft rejection.

Another interesting possibility is that the PT and class II-expressing epithelial cells in general, may play a unique antigen presenting role in vivo. Thymic epithelial class II expression is critical to the positive selection of the mature $\mathrm{CD}^{+} \mathrm{T}$ cell repertoire (51). Studies by Lefrancois et al. (52) strongly suggest an extrathymic selection mechanism for $\gamma \delta$-T cells that appears to depend on class II MHC expression. In addition, studies by Rocha et al. $(53,54)$ have shown that peripheral selection of the $\alpha \beta$-T cell repertoire also occurs for $\mathrm{CD} 8^{+} \mathrm{T}$ cells. Although this selection process may occur on the gut epithelium, it is also possible that selection might occur on the PT epithelium. The affinity model of $T$ cell selection postulates that the interaction of the thymocyte TCR with MHC/ligand must be of high enough avidity that the cell is rescued from programmed cell death but of low enough avidity that the cell is not negatively selected. The interaction of Th1 TCR with PT class II MHC/antigen would seem to fall within this spectrum of interaction.

In summary, we have described a cell population with a unique antigen-presenting function compared to other professional APC. KTC can process and present foreign as well as self protein antigens yet fail to stimulate $\mathrm{Th} 1$ clone proliferation or IL-2 production, at least in part due to regulation of the costimulator B7. Interestingly, the KTC do not simply behave as costimulator-deficient professional APC since they do not reliably induce anergy in the Thl clones, a phenotype distinct from that of professional APC. However, transfection of B7 allows the Th1 clones to proliferate to antigen presented by the KTC. These results show that class II MHC-expressing epithelial cells lacking B7 stimulate but fail to induce anergy in Th1 clones. T cell mediated renal interstitial nephritis may reflect loss of the normal ability of the KTC to limit B7 expression. These results have important implications for understanding and perhaps developing new therapies for renal interstitial nephritis.

\section{Acknowledgments}

We thank Marlo Meyer and Therica Nelson for technical assistance. We also thank Drs. Casey Weaver (Department of Pathology, University of Alabama at Birmingham, Birmingham, AL), Ralph Brinster (University of Pennsylvania, Philadelphia, PA), Anand Dighe, Robert D. Schreiber, and Terecita Yule (Department of Pathology, Washington University School of Medicine), and Hans Reiser (Dana Farber Cancer Institute, Boston, MA) for providing valuable reagents. In addition, we gratefully acknowledge Dr. L. Lee Hamm (Section of Nephrology, Tulane University School of Medicine, New Orleans, LA) for microdissection of proximal tubule segments from the SV40-transformed mice.

This work was supported by National Institutes of Health Grant AI-24157. Dr. Allen is an Established Investigator of the American Heart Association. Dr. Hagerty was supported by Physician Scientist Award AI-00969 from National Institute of Allergy and Infectious Diseases.

\section{References}

1. Bland, P. 1988. MHC class II expression by the gut epithelium. Immunol. Today. 9:174-178.

2. Unanue, E. R., and P. M. Allen. 1986. Comment on the finding of la expression in nonlymphoid cells. Lab. Invest. 55:123-125.

3. Kaiserlian, D., K. Vidal, and J.-P. Revillard. 1989. Murine enterocytes can present soluble antigen to specific class II-restricted CD4+ T cells. Eur. J. Immunol. 19:1513-1516.

4. Hart, D. N. J., and J. W. Fabre. 1981. Endogenously produced Ia antigens within cells of convoluted tubules of rat kidney. J. Immunol. 126:2109-2114.

5. Mayrhofer, F., and M. A. Schon-Hegrad. 1983. Ia antigens in rat kidney, with special reference to their expression in tubular epithelium. J. Exp. Med. 157:2097-2109.

6. Hagerty, D. T., and P. M. Allen. 1992. Processing and presentation of self and foreign antigens by the renal proximal tubule. J. Immunol. 148:2324-2330.

7. Sinclair, G. C., A. Wadgymar, P. F. Halloran, and T. L. Delovitch. 1984. Graft-vs.-host reactions induce $\mathrm{H}-2$ class II gene transcription in host kidney cells. Immunogenetics. 20:503-511.

8. Benson, E. M., R. B. Colvin, and P. S. Russell. 1985. Induction of Ia antigens in murine renal transplants. J. Immunol. 134:7-9.

9. Schainuck, L. I., G. E. Striker, R. E. Cutler, and E. P. Benditt. 1970. Structural-functional correlations in renal disease. II. The correlations. Hum. Pathol. 1:631-640.

10. Bohle, A., H. V. Gise, S. Mackensen-Haen, and B. Stark-Jakob. 1981. The obliteration of the postglomerular capillaries and its influence upon the function of both glomeruli and tubuli. Klin. Wochenschr. 59:1043-1051.

11. Bohle, A., S. Mackensen-Haen, and H. Gise. 1991. The consequences of tubulointerstitial changes for renal function in glomerulopathies. In Tubulo-Interstitial Nephropathies. A. Amerio, P. Coutelli, and S. E. Massuy, editors. Kluwer, Boston. 29-40.

12. Eddy, A. A., L. McCulloch, E. Liu, and J. Adams. 1991. A relationship between proteinuria and acute tubulointerstitial disease in rats with experimental nephrotic syndrome. Am. J. Pathol. 138:1111-1123.

13. Bertani, T., F. Cutillo, C. Zoja, M. Broggini, and G. Remuzzi. 1986 Tubulo-interstitial lesions mediate renal damage in adriamycin glomerulopathy. Kidney Int. 30:488-496.

14. Hooke, D. H., D. C. Gee, and R. C. Atkins. 1987. Leukocyte analysis using monoclonal antibodies in human glomerulonephritis. Kidney Int. 31:964972.

15. Alexopoulos, E., D. Seron, R. B. Hartley, and J. S. Cameron. 1990. Lupus nephritis: correlation of interstitial cells with glomerular function. Kidney Int. 37:100-109.

16. Li, H. L., W. W. Hancock, D. H. Hooke, J. P. Dowling, and R. C. Atkins. 1990. Mononuclear cell activation and decreased renal function in IgA nephropathy with crescents. Kidney Int. 37:1552-1556. 
17. Wuthrich, R. P., L. H. Glimcher, M. A. Yui, A. M. Jevnikar, S. E. Dumas, and V. E. Kelley. 1990. MHC class II, antigen presentation and tumor necrosis factor in renal tubular epithelial cells. Kidney Int. 37:783-792.

18. Wuthrich, R. P., M. A. Yui, G. Mazoujian, N. Nabavi, L. H. Glimcher, and V. E. Kelley. 1989. Enhanced MHC class II expression in renal proximal tubules precedes loss of renal function in MRL/lpr mice with lupus nephritis. Am. J. Pathol. 134:45-51.

19. Weaver, C. T., and E. R. Unanue. 1990. The costimulatory function of antigen presenting cells. Immunol. Today. 11:49-55.

20. Evavold, B. D., S. G. Williams, B. L. Hsu, S. Buus, and P. M. Allen. 1992. Complete dissection of the $\mathrm{Hb}(64-76)$ determinant using Th1, Th2 clones, and $\mathrm{T}$ cell hybridomas. J. Immunol. 148:347-353.

21. Yule, T. D., A. Basten, and P. M. Allen. 1993. HEL-specific T cells elicited in HEL-transgenic mice retain an imprint of self-tolerance. J. Immunol. 151:3057-3069.

22. Vinay, P., A. Gougoux, and G. Lemieux. 1981. Isolation of a pure suspension of rat proximal tubules. Am. J. Physiol. 241:F403-F411.

23. Hawrylowicz, C. M., and E. R. Unanue. 1988. Regulation of antigen-presentation I. IFN- $\gamma$ induces antigen-presenting properties on B cells. J. Immunol. 141:4083-4088.

24. Wang, R., K. M. Murphy, D. Y. Loh, C. Weaver, and J. H. Russell. 1993. Differential activation of antigen-stimulated suicide and cytokine production pathways in CD4+ T cells is regulated by the antigen-presenting cell. J. Immunol. 150:3832-3842.

25. Gough, N. M. 1988. Rapid and quantitative preparation of cytoplasmic RNA from small numbers of cells. Anal. Biochem. 173:93-95.

26. Lorenz, R. G., and P. M. Allen. 1988. Direct evidence for functional self protein/la-molecule complexes in vivo. Proc. Natl. Acad. Sci. USA 85:52205223.

27. Hagerty, D. T., B. D. Evavold, and P. M. Allen. 1991. The processing and presentation of the self-antigen hemoglobin: self-reactivity can be limited by antigen availability and co-stimulator expression. J. Immunol. 147:3282-3288.

28. Jenkins, M. K., and R. H. Schwartz. 1987. Antigen presentation by chemically modified splenocytes induces antigen-specific $T$ cell unresponsiveness in vitro and in vivo. J. Exp. Med. 165:302-319.

29. Russell, J. H., C. L. White, D. Y. Loh, and P. Meleedy-Rey. 1991. Receptor-stimulated death pathway is opened by antigen in mature T cells. Proc. Natl. Acad. Sci. USA. 88:2151-2155.

30. Mueller, D. L., M. K. Jenkins, and R. H. Schwartz. 1989. Clonal expansion vs. functional clonal inactivation. Annu. Rev. Immunol. 7:445-480.

31. Linsley, P. S., W. Brady, L. Grosmaire, A. Aruffo, N. K. Damle, and J. A. Ledbetter. 1991. Binding of the B cell activation antigen B7 to CD28 costimulates $\mathrm{T}$ cell proliferation and interleukin 2 mRNA accumulation. J. Exp. Med. 173:721-730.

32. Liu, Y., B. Jones, A. Aruffo, K. M. Sullivan, P. S. Linsley, and C. A. Janeway, Jr. 1992. Heat-stable antigen is a costimulatory molecule for CD4 T cell growth. J. Exp. Med. 175:437-445.

33. Beller, D. I., J.-M. Kiely, and E. R. Unanue. 1982. Regulation of macrophage populations. I. Preferential induction of Ia-rich peritoneal exudates by immunologic stimuli. J. Immunol. 124:1426-1432.

34. Bancroft, G. J., R. D. Schreiber, G. C. Bosma, M. J. Bosma, and E. R. Unanue. 1987. A $T$ cell-independent mechanism of macrophage activation by interferon- $\gamma$. J. Immunol. 139:1104-1107.

35. Skoskiewicz, M. J., R. B. Colvin, E. E. Schneeberger, and P. S. Russell. 1989. Widespread and selective induction of major histocompatibility complexderived antigens in vivo by gamma interferon. J. Exp. Med. 162:1645-1664.
36. Ding, L., P. S. Linsley, L.-Y. Huang, R. N. Germain, and E. M. Shevach 1993. IL-10 inhibits macrophage costimulatory activity by selectively inhibiting the up-regulation of B7 expression. J. Immunol. 151:1224-1234.

37. Nabavi, N., Z. Ghogawala, A. Myer, I. J. Griffith, W. F. Wade, Z. Z. Chen, D. J. McKean, and L. H. Glimcher. 1989. Antigen presentation abrogated in cells expressing truncated Ia molecules. J. Immunol. 142:1444-1447.

38. Cambier, J. C., M. K. Newell, L. B. Justement, J. C. McGuire, K. L. Leach, and Z. Z. Chen. 1987. Ia binding ligands and cAMP stimulate nuclear translocation of PKC in B lymphocytes. Nature (Lond.). 327:629-632.

39. Nabavi, N., G. J. Freeman, A. Gault, D. Godfrey, L. M. Nadler, and L. H. Glimcher. 1992. Signalling through the MHC class II cytoplasmic domain is required for antigen presentation and induces B7 expression. Nature (Lond.). 360:266-268.

40. Dustin, M. L., and T. A. Springer. 1989. T-cell receptor cross-linking transiently stimulates adhesiveness through LFA-1. Nature (Lond.). 341:619624.

41. Lorenz, R. G., and P. M. Allen. 1989. Thymic cortical epithelial cells lack full capacity for antigen presentation. Nature (Lond.). 340:557-559.

42. Bretscher, P., and M. Cohn. 1970. A theory of self-nonself discrimination. Science (Wash. DC). 169:1042-1049.

43. Burkly, L. C., D. Lo, and R. A. Flavell. 1990. Tolerance in transgenic mice expressing major histocompatibility molecules extrathymically on pancreatic cells. Science (Wash. DC). 248:1364-1368.

44. Gonias, S. L., S. V. Pizzo, and M. Hoffman. 1988. Clearance and distribution of recombinant murine $\gamma$-interferon in mice. Cancer Res. 48:2021-2024.

45. Jenkins, M. K., J. D. Ashwell, and R. H. Schwartz. 1988. Allogeneic non- $\mathrm{T}$ spleen cells restore the responsiveness of normal $\mathrm{T}$ cell clones stimulated with antigen and chemically modified antigen-presenting cells. J. Immunol. 140:3324-3330.

46. Liu, Y., and C. A. Janeway, Jr. 1993. Cells that present both specific ligand and costimulatory activity are the most efficient inducers of clonal expansion of normal CD4 T cells. Proc. Natl. Acad. Sci. USA. 89:3845-3849.

47. Kelly, C. J. 1990. T cell regulation of autoimmune interstitial nephritis. $J$. Am. Soc. Nephrol. 1:140.

48. Zakheim, B., E. McCafferty, S. Michael-Phillips, M. Clayman, and E. G. Neilson. 1984. Murine interstitial nephritis. II. The adoptive transfer of disease with immune $\mathrm{T}$ lymphocytes produces phenotypically complex interstitial lesion. J. Immunol. 133:234-239.

49. Mann, R., B. Zakheim, M. D. Clayman, E. McCafferty, L. Michaud, and E. G. Neilson. 1985. Murine interstitial nephritis. IV. Long-term cultured L3T4+ $\mathrm{T}$ cell lines transfer delayed expression of disease as I-A-restricted inducers of the effector T cell repertoire. J. Immunol. 135:286-293.

50. Haverty, T. P., C. J. Kelly, W. H. Hines, P. S. Amenta, M. Watanabe, P. A Harper, N. A. Kefalides, and E. G. Neilson. 1988. Characterization of a rena tubular epithelial cell line which secretes the autologous target antigen of autoimmune experimental interstitial nephritis. J. Cell Biol. 107:1359-1368.

51. von Boehmer, H., H. S. Teh, and P. Kisielow. 1989. The thymus selects the useful, neglects the useless and destroys the harmful. Immunol. Today. 10:5761 .

52. Lefrancois, L., R. LeCorre, J. Mayo, J. A. Bluestone, and T. Goodman. 1990. Extrathymic selection of TCR $\gamma \delta+$ T cells by class II major histocompatibility complex molecules. Cell. 63:333-340.

53. Rocha, B., and H. von Boehmer. 1991. Peripheral selection of the T cell repertoire. Science (Wash. DC). 251:1225-1228.

54. Rocha, B., H von Boehmer, and D. Guy-Grand. 1992. Selection of intraepithelial lymphocytes with CD8 $\alpha / \alpha$ co-receptors by self-antigen in the murine gut. Proc. Natl. Acad. Sci. USA. 89:5336-5340. 